\title{
Estimation of Recreational Value of Horton Plains National Park in Sri Lanka: A Decision Making Strategy for Natural Resources Management
}

\author{
R. M. W. Rathnayake*1 and U. A. D. P. Gunawardena ${ }^{2}$ \\ ${ }^{1}$ Department of Tourism Management, Sabaragamuwa University of Sri Lanka, Sri Lanka \\ ${ }^{2}$ Department of Forestry and Environmental Sciences, \\ University of Sri Jayewardenepura, Sri Lanka \\ Date Received: 06-08-2011 Date Accepted: 04-10-2011
}

\begin{abstract}
Horton Plains National Park (HPNP) is an area of high biodiversity and exceptional endemism receiving high visitation (166,613 visitors in 2009), both by local and foreigners. Although, tourism causes negative impacts on the environment, environmental valuation could be used for taking decisions on natural resources management. The study shows that the recreational value of HPNP is Rs. 51.68 million rupees per year, but the total economic value could be many times higher than this. Calculations showed the maximum revenue from the park could be obtained if the entrance fee is raised to Rs. 472.00. This may however reduce the present visitor number by $65 \%$, but it will improve the total revenue of the park by $314 \%$. These differences strengthen the common argument by both officials and the public regarding insufficient allocation of man power and funds for natural resources management.
\end{abstract}

Key words: wildlife, recreational value, travel cost method

\footnotetext{
* Correspondence: Email: warath1@gmail.com

Tel:+94 7144 47767, Fax:+94 452280296

ISSN 2235-9370 Print/ ISSN 2235-9362 Online (C2011 University of Sri Jayewardenepura
} 
Rathnayaka \& Gunawardena /Journal of Tropical Forestry and Environment Vol. 01, No. 01 (2011) 71-86

\section{Introduction}

Official records state that the about 14 per cent of the land area is protected by the Department of Wildlife Conservation in Sri Lanka, one of the highest proportions in Asia (DWC, 2001: FSMP, 1995). In Sri Lanka, national parks are the only protected areas, which permit recreation. The national parks get more than half a million visitors a year, about $20 \%$ of who are foreigners. Presently, tourism is the fourth revenue earning industry in Sri Lanka (CBSL, 2009).

Eonomics of outdoor recreation deals with the supply of and demand for natural resources for recreational purposes (McConnell 1985). Some methods were developed for estimating the economic value of nonmarket environmental goods such as parks and recreation areas in the last 50 years. These methods may be divided into two groups: revealed preference and stated preference methods.

It is recorded that after the civil war in Sri Lanka, visitation to the national parks has drastically increased. For example in 2010, the national parks of Sri Lanka received 756,783 visitors including foreign visitors, and earned Rs. 412.5 millions. The increasing visitation to the national park system is making it more difficult for the National Park Service to fulfill its dual mission of providing high quality recreational experience for the public while conserving resources for future generations. Concern over rising visitation in parks, and accompanying impacts on resources and on visitor experience, has led the National Park Service to focus increasing attention on the concept of carrying capacity.

Due to market failures and imperfections, the entrance fees of the parks do not reflect the true value of the resource. Such under valuation could lead to their over use and rapid degradation (Hufschmidt et al., 1983) and economists show growing interest on valuation of environmental amenities. The process of valuation provides protected area managers with information about the protected area's goods and services, the values which people (potential supporters or customers) place on those, which values are being captured and which are not, and which groups could derive more benefits through alternative uses of the protected area and are therefore inclined to be a 'threat' to the protected area. In this way, valuation provides useful information for management and financing decisions regarding protected areas, especially such estimated values could be used to decide appropriate user/entrance fee and recreational value which could be used to guide investment on parks.

The paucity of environmental valuation information on Sri Lankan protected areas is still a serious drawback for proper management and conservation. Inadequate funds to maintain a national park is one of the major problems faced by the wildlife authorities. A greater part of the services of a national park is felt in the category of 'externalities' hence it is not accurately valued and appropriated by the market mechanism. Thus planners, guided by market values, tend to misallocate financial and other resources for the management of protected areas, resulting in mismanagement of the resource (Rathnayake \& Gunewardena, 2009).

The Travel Cost Method (TCM) is the most common revealed preference method used to estimate the recreational use value of natural areas. This method was initially suggested by Harold Hotelling in the 1930s as a potential means of valuing national parks. Clawson and Knetsch developed Hotelling's approach and used the name Travel Cost Method (Tisdell, 1991). The Travel Cost Method is applied in two different ways, namely the Individual Travel Cost Method (ITCM) and the Zonal Travel Cost Method (ZTCM). 
The TCM is selected in the present study for two main reasons:

1. The site is primarily valuable to people as a recreational site. The existing endangered species and other highly unique qualities that would make values for the site significant.

2. The expenditure for carrying out a Travel Cost study is relatively low

The objective of this study is therefore to estimate the recreational value (which is part of the total economic value) of the HPNP to facilitate national decision making during resource allocation and nature tourism promotion in HPNP. In addition, this study aims to estimate appropriate user fee which gives the maximum revenue for HPNP.

\section{Literature Review}

Several studies have been done in Sri Lanka to estimate the recreational value of national parks. De Silva and Kotagama (1997) estimated the consumer surplus of Uadawalawe National Park as Rs. 2.18 millions. Rathnayake and Gunewardene $(2002 ; 2009)$ could estimate the recreational value of three national parks in Sri Lanka. Rs. 2.38 millions for Wasgmauwa National Park, and Rs. 1.92 millions for Kawdulla National Park. Sooriyabandara (2002) estimated the recreational value of Minneriya National Park as Rs. 3.9 million. Compared to other studies, the recreational value of Yala National park was Rs.54.4 millions (Marasinghe, 2002). Guntilake \& Vieth (1998) estimated the recreational value of Pinnawela Elephant Orphanage which is a zoological garden, and that was Rs. 12.2 millions. In addition to these studies, the recreational value of some of Botanic Gardens also have been estimated. Abeygunawardena and Kodithuwakku (1992) applied travel cost method for recreational valuation of Peradeniya Botanic Garden. Further, Rathnayake \& Kariyawasam (2002) estimated the recreational value of Peradeniya Botanic Garden as Rs. 240 millions, and according to Jayaratne and Gunawardena (2004), that value is Rs. 221 millions for Hakgala Botanic Garden. The zonal travel cost method was employed by Piydasa \& Thiruchelvam (2005) for Bopath Ella, and the estimated total recreation value was Rs. 120 million per year. Using discount rates of $8 \%$ and $6 \%$, the present values of total consumer surplus were Rs. 1820 million and Rs. 2000 million per year, respectively. It is found that the recreational value of urban areas such as Diywanna Oya (Parliament Ground) is many times higher than the protected areas. That value was Rs. 3890 millions (Marawila and Thibbotuwawa, 2010).

\section{Methodology}

\subsection{Study Area}

Horton Plains National Park (HPNP) is located approximately between the latitudes $6^{0} 47^{\prime}$ to $6^{0} 50^{\prime \prime}$ $\mathrm{N}$ and longitudes $80^{\circ} 46^{\prime}$ and $80^{\circ} 50^{\prime} \mathrm{E}$ (DWC 1997). The Horton Plains National Park (HPNP) is situated in the south of Nuwara Eliya district and forms a plateau in the southeastern corner of the main ridge of Sri Lanka's central mountain massif. The HPNP forms the highest tableland in Sri Lanka, with altitude ranging from $2100 \mathrm{~m}$ to $2300 \mathrm{~m}$. The mountain peaks of Kirigalpotta $(2389 \mathrm{~m})$ and Totupolakanda $(2357 \mathrm{~m})$, the second and third highest mountains in the island, arise from these plains. The Horton Plains received its name in hounour of Sri Wilmot Horton, a former British Covernor of Ceylon. The 
3162 ha area, that forms the national park now, was first established as a Nature Reserve in 1969 and then re-designated as a national park in 1988. HPNP is an area of high biodiversity and exceptional endemism. Therefore, HPNP is richer in endemic fauna and flora compared to other protected areas in Sri Lanka. HPNP is unique among other national parks of Sri Lanka, where visitors are allowed walk along the nature trails in the unique scenic landscape, and the highest number of visitors are recorded in this national park (166,613 visitors in 2009). The park is located $160 \mathrm{~km}$ away from Colombo.

\subsection{Method}

\subsubsection{Theory of Travel Cost Method (TCM)}

The basic method of travel cost assumes that visitors visit only a single site. The basis of the travel cost method is as follows. If an individual's utility depends on the total time spent at the considered site, the quality of the site, bundle of other commodities, the individual visitor would maximize the following utility function,

$$
\operatorname{Max}: u(X, r, q)
$$

Where $\mathrm{X}=$ Bundle of Other Commodities

$r \quad=$ Number of visits to the site

$\mathrm{q}=$ Quality of the site

In maximization of above utility function the individual is constrained by the following commodities.

$$
M+p_{w} t_{w}=X+c . r
$$

Where $\mathrm{M}=$ Exogenous income

$\mathrm{pw}=$ Wage rate

tw $=$ Hours of work

c = Monetray cost of a trip

$t^{*}=t_{w}+\left(t_{1}+t_{2}\right) r$

$$
\begin{aligned}
\text { Where } & \mathrm{t}^{*}=\text { Total discretionary time } \\
\mathrm{tw} & =\text { Hours of work } \\
\mathrm{t}_{1} & =\text { Round trip travel time } \\
\mathrm{t}_{2} & =\text { Time spent at site }
\end{aligned}
$$


Assumptions:

1. $\mathrm{r}$ and $\mathrm{q}$ are compliments in the utility function

2. Individual is fare to choose the time spent at work and work does not convey utility or distillate directly

3. Monetary cost to the site has two components, namely the entrance fee and the monetary cost of travel (cost is pd . $\mathrm{d}$ where pd is per kilometer cost and $\mathrm{d}$ is distance)

Substituting (3) into (2)

$$
M+p_{w} . t^{*}=X+r\left[c+p_{w}\left(t_{1}+t_{2}\right)\right]
$$

Equation (4) shows that the individual income is spent totally on consuming a bundle of other commodities and a visit to the recreation site. The income has two components, exogenous income and the potential income which could be generated by allocating all the available time for work.

So the utility maximization problem of the individual can be shown as;

$\operatorname{Max}: \mathrm{u}(\mathrm{X}, \mathrm{r}, \mathrm{q})$

$$
\text { St. } M+p w \cdot t^{*}=X+r\left(f+p_{d .} d+p_{w}\left(t_{1}+t_{2}\right)\right.
$$

The Lagrangian function of the maximization problem is:

$$
L=u(X, r, q)+\lambda\left(M+p_{w} t^{*}-\left[X+r\left[f+p_{d} d+p_{w}\left(t_{1}+t_{2}\right)\right]\right]\right)(6)
$$

Where $\mathrm{f}=$ Entrance fee

$\mathrm{pd}=$ Cost per kilometer

$\mathrm{d}=$ Travel distance in kilometers

the first order necessary conditions are

$$
\begin{aligned}
& \frac{\partial u}{\partial x}=\lambda \\
& \frac{\partial u}{\partial r}=\lambda\left\{f+p_{d} \cdot d+p_{w}\left(t_{1}+t_{2}\right)\right\} \\
& M+p_{w} t^{*}=X+r\left\{f+p_{d} \cdot d+p_{w}\left(t_{1}+t_{2}\right)\right\}
\end{aligned}
$$

Where ë is marginal utiliy of money income.

The maximization of utility equation subject to the constraint equation results in the individual's demand function for visits 


$$
\mathrm{r}=\mathrm{r}(\mathrm{pr}(\mathrm{f}, \mathrm{pd}, \mathrm{d}, \mathrm{pw}, \mathrm{t} 1, \mathrm{t} 2), \mathrm{M}, \mathrm{q})
$$

The model is derived for an individual and estimating the demand function requires time series data on the number of visits of each visitor. Since it is difficult to collect such a data set, an alternative method is used instead. The country is divided into regions and the visit rate from each region is calculated instead of the visit rate of the individuals. It is assumed that the visitors from one region have the same characteristics. The regional visit rate is assumed as a proxy for the quantity demanded for recreation. Visitors from a shorter regional distance to the site are expected to have a higher visit rate from a greater regional distance since the travel and the time cost is lower for closer regions. The visit rate and the travel cost have a negative relation in congruence with the law of demand. The estimated demand function could be used in calculating consumer surplus, which is the value of the national park as given in equation (9).

$$
V=\int_{p 1}^{p 2} r\left[p_{r}\left(f, p_{d}, d, p_{w}, t_{1}, t_{2}\right) M, q\right]
$$

$$
\text { Where } \begin{aligned}
\mathrm{V} & =\text { value of national park } \\
\mathrm{P}_{1} & =\text { Lowest total price of recreation } \\
\mathrm{P}_{2} & =\text { Highest total price of recreation }
\end{aligned}
$$

\subsubsection{Survey design and Data collection \& Questionnaire survey}

The visitors to the park were first divided into two categories i.e. local and overseas visitors. The overseas visitors have been omitted from the study to avoid the extremes that would come up due to their high purchasing power and other fees charged (i.e. transportation, lodging, entrance etc.) compared to local visitors and to avoid multiple visitor issues. Data for the study were collected from both primary and secondary sources. Secondary data were collected (number of visitors to the HPNP) from the visitor statistics maintained by the park wardens.

Primary data were collected from a field questionnaire survey. Visitors were interviewed on site individually. Basically the questionnaire was designed to collect the information indirectly. The questionnaire consisted of 19 sub questions/sections. Information on area of residence, socio economic features, their visitation rates to HPNP, willingness to see wildlife, information on round trip mileage, travel costs, opportunity cost of travel time, length of the trip, time spent at the site, other locations visited during the same trip, quality of the recreational experience and perceptions of environmental quality at the site were obtained from the questionnaire. A separate question was directed on their proposed park entrance fee. This questionnaire was pre-tested with 15 visitor groups for clarification of feasibility of data collection before the study. The questionnaire survey was administered for the randomly selected visitors from $07.00 \mathrm{hrs}$ to $17.00 \mathrm{hrs}$ during January 2007 to December 2007. The survey was conducted both in weekdays and weekends.

Only seventeen districts were selected as the zones because according to the results of the pretest, number of visitors was very low from other regions during the period of the study. According to the 
questionnaire survey visitors were very rarely (less than 5\%) recorded from some districts. The past data on visitor statistics also proved this. These districts approximately lie within the concentric circles of the study sites.

The information on the number of visitors from above districts in 2007 was collected from the visitor statistics database of Department of Wild life Conservation. The visitation rates per 1000 population in each district/zone were estimated using the following equation (10).

$$
\begin{aligned}
& \text { Visitation rate/1000/year }=\frac{\left(V_{i / n}\right) N \times 1000}{P_{i}} \\
& \text { Where } \mathrm{V}_{\mathrm{i}}=\text { visitors from } \mathrm{i}^{\text {th }} \text { zone, } \\
& \mathrm{n}=\text { sample size, } \\
& \mathrm{N}=\text { total number of visitors per year } \\
& \mathrm{P}_{\mathrm{i}}=\text { Population in } \mathrm{i}^{\text {th }} \text { zone }
\end{aligned}
$$

\subsubsection{Total Travel Cost (TTC) estimation}

Total travel cost includes both travel cost and opportunity cost of time. Travel cost refers to the direct expenses incurred by visitors in getting to and from the site including fare, fuel, fees and other incidentals (OECD, 1995). Opportunity cost of time is the value of time spent on the journey including time spent at the site. It is assumed that the people in zone ' 0 ' have zero travel distance and time. Each other zone will have an increasing travel time and distance. At present the park entrance fee to HPNP is Rs. 60.00, although during the study period that fee was Rs.40.00, and that fee was considered in TTC.

The value of time is calculated by using the following formulae (11):

Value of time $(\mathrm{Rs})$ hour $=\frac{(M I / 30)}{8}$

Where, $\mathrm{MI}=$ average monthly income of each zone

$$
30 \text { = days per month; } \quad 8=\text { working hours per day }
$$

\subsubsection{Obtaining the statistical regression}

This was done to test (to explain visitation rates in terms of travel costs) the relationship between visitation rates and respective travel costs through a linear regression. Minitab statistical package was used for analysis.

\subsubsection{Construction of the demand curve}

If the visitation rates of the park users can be shown as a function of the 'Price' paid, for which travel cost is a proxy, the relationship can be taken a 'demand curve' for wildlife viewing at HPNP. Given a demand function relating visitation rates to travel cost, the final step was to 'anchor' the data to the actual level of visits, and generate points on the demand curve iteration. 
Zonal visitation rate per thousand population with respect to travel costs were used to estimate the demand equation for wildlife viewing. The same equation was used with data on travel costs to trace out changes in demand for visits with increasing admission fees. The area under this curve is calculated assuming that the demand curve is linear between any two points. According to Figure 2, consumer surplus is the area under the demand curve above price line. In absence of an entrance fee, the entire area under the demand curve was considered as the consumer's surplus for viewing wildlife and it is equal to the total recreational value.

\subsubsection{Determination of price which gives the maximum revenue}

The actual visitor number with a higher entrance fee is the number of visitors of all studied zones with respect to each proposed total travel cost with higher entrance fee, Once the actual zonal number (Q) were obtained, the total revenue (TR) can be calculated by multiplying the $\mathrm{Q}$ by respective fee $(\mathrm{P})$.

$\mathrm{Q}$ is first regressed against the respective $\mathrm{P}$ and the appropriate regression equation was obtained. Here, when P reaches zero, $Q$ will be maximized and when $P$ is at a maximum $Q$ will be zero. The TR is plotted against $\mathrm{Q}$ to obtain the point which gives the maximum revenue ( $\operatorname{Tr} \max )$. This is shown in Figure 3.

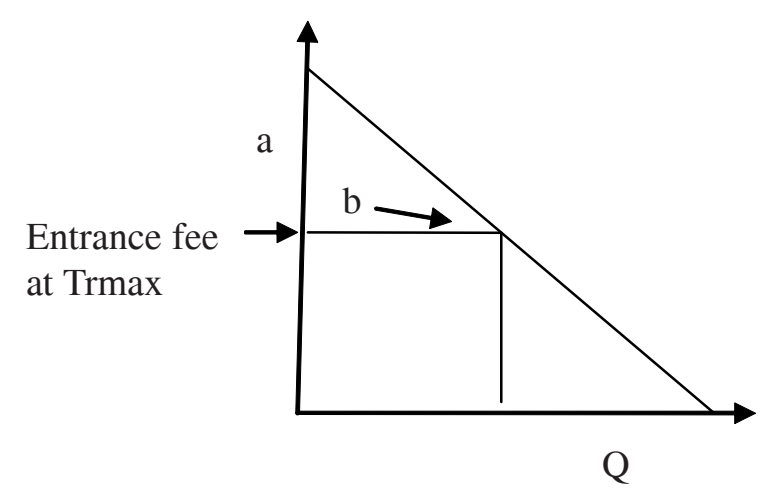

Figure 2: Demand curve for recreation

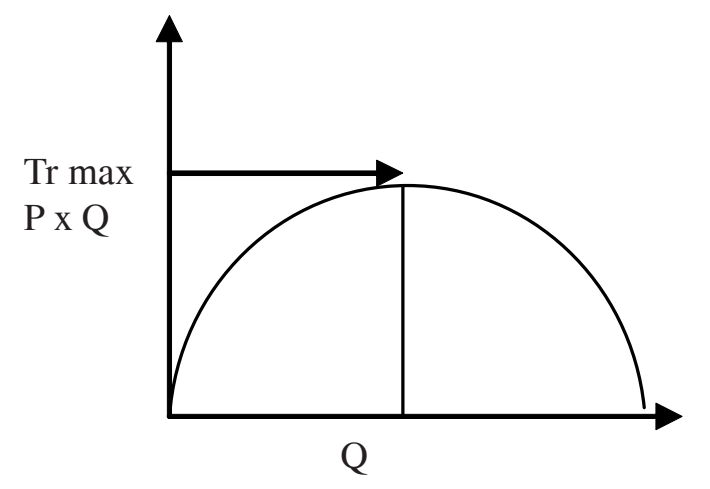

Figure 3: Relationship between total revenue and Q

$$
\begin{aligned}
\mathrm{a} & =\text { intercept } \\
\mathrm{b} & =\text { slope } \\
\mathrm{P} & =\mathrm{a}-\mathrm{bQ} \ldots \ldots . \\
\mathrm{TR} & =\mathrm{P} \times \mathrm{Q}
\end{aligned}
$$

From Figure 1,

$$
\begin{aligned}
\mathrm{P} & =\mathrm{a}-\mathrm{bQ} \\
\mathrm{TR} & =(\mathrm{a}-\mathrm{bQ}) \mathrm{Q} \\
& =\mathrm{aQ}-\mathrm{bQ}^{2}
\end{aligned}
$$


When TR is maximum (TRmax)

$\frac{d T R}{d Q}=1-2 \mathrm{bQ}=0$

Then, $\mathrm{a}=2 \mathrm{bQ}$

$\mathrm{Q}=\mathrm{a} / 2 \mathrm{~b}$

According to equation (12), $\mathrm{Q}$ can be calculated because $\mathrm{a}$ and $\mathrm{b}$ is given in the regression equation of $\mathrm{P}$ and $\mathrm{Q}$. Once $\mathrm{Q}$ is calculated it can be substituted in the above formulae to get the appropriate price level. This is the price or the maximum revenue, which should be charged as the entrance fee.

\section{Results and Discussion}

The total number visitors and the origin of the place of travel of each visitor were recorded for a period of twelve months in 2007. Even though 200 visitors were interviewed, a few had to be discarded due to information errors. The remainder of the visitors was from 17 districts and their visitation rates were also calculated (Table 1). According to the data collected, most of the visitors were from Colombo and Gampaha districts. The lowest visitation rate was recorded from the Polonnaruwa district.

Table 1: Visitation Rates for HPNP

\begin{tabular}{lccc}
\hline Zone & $\begin{array}{c}\text { Population in } \\
2006\end{array}$ & $\begin{array}{c}\text { No. oc } \\
\text { Respondents }\end{array}$ & Visitation Rate (VR) \\
\hline Anuradhapura & 791000 & 5 & 4.82 \\
Ampara & 627000 & 3 & 3.65 \\
Badulla & 837000 & 13 & 11.84 \\
Colombo & 2421000 & 28 & 8.82 \\
Galle & 1040000 & 13 & 9.53 \\
Gampaha & 2125000 & 25 & 8.97 \\
Hambantota & 547000 & 3 & 4.18 \\
Kalutara & 1102000 & 15 & 10.38 \\
Kandy & 1361000 & 14 & 7.85 \\
Kegalle & 797000 & 12 & 11.49 \\
Kurunegala & 1511000 & 10 & 5.05 \\
Matale & 471000 & 5 & 8.09 \\
Matara & 804000 & 65.69 & \\
Moneragala & 420000 & 5 & 9.08 \\
Nuwara Eliya & 735000 & 14 & 14.53 \\
Polonnaruwa & 382000 & 2 & 3.99 \\
Ratnapura & 1073000 & 10 & 7.11 \\
\hline
\end{tabular}


The visitor information reveled that the highest total travel cost was from the Anuradhapura District, but the opportunity cost of time of Colombo visitors was higher than all other districts (Table 2). The lowest total cost is recorded from the district of Nuwara Eliya district, because it is closer to HPNP, due to the lower opportunity cost of time.

Table 2: Time costs, Travel costs and Total travel costs to HPNP

\begin{tabular}{lccc}
\hline Zone & Travel Cost (Rs.) & Time Cost (Rs.) & TTC \\
\hline Anuradhapura & 967 & 415 & 1382 \\
Ampara & 876 & 400 & 1276 \\
Badulla & 486 & 395 & 881 \\
Colombo & 695 & 493 & 1188 \\
Galle & 618 & 452 & 1070 \\
Gampaha & 620 & 465 & 1085 \\
Hambantota & 663 & 402 & 1065 \\
Kalutara & 583 & 457 & 1040 \\
Kandy & 627 & 425 & 1052 \\
Kegalle & 670 & 405 & 1075 \\
Kurunegala & 721 & 434 & 1155 \\
Matale & 653 & 420 & 1073 \\
Matara & 524 & 410 & 934 \\
Moneragala & 510 & 380 & 890 \\
Nuwara Eliya & 264 & 325 & 589 \\
Polonnaruwa & 691 & 388 & 1079 \\
Ratnapura & 815 & 447 & 1262 \\
\hline
\end{tabular}

The travel cost function was estimated using the ordinary least square method (OLS). The estimated regression function is significant and the adjusted $\mathrm{R}^{2}$ (measure for goodness of fit) is acceptable at 41.6 $\%$. In this study, only total travel cost value was considered.

The regression equation is

$$
\begin{aligned}
& \text { VR }=20.3411-0.0116450 \text { TTC } \\
& (\mathrm{S}=2.37743 \quad \mathrm{R}-\mathrm{Sq}=45.3 \% \quad \mathrm{R}-\mathrm{Sq}(\operatorname{adj})=41.6 \%) \\
& \mathrm{n} \quad=17, \text { SE coefficient- } 3.567
\end{aligned}
$$




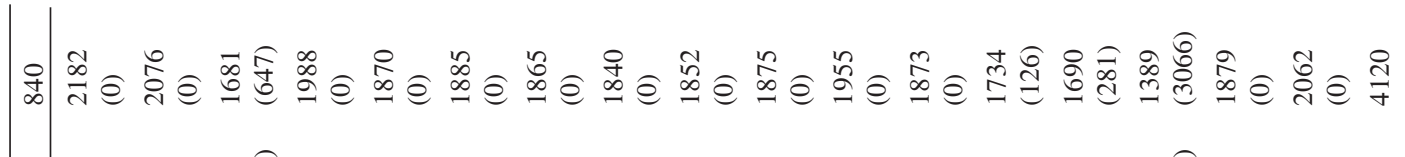

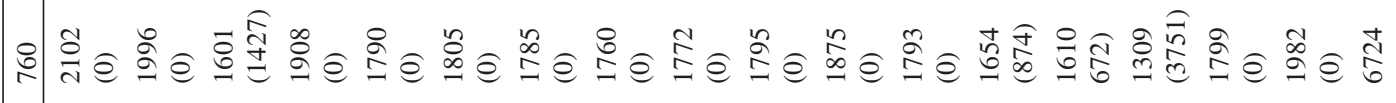

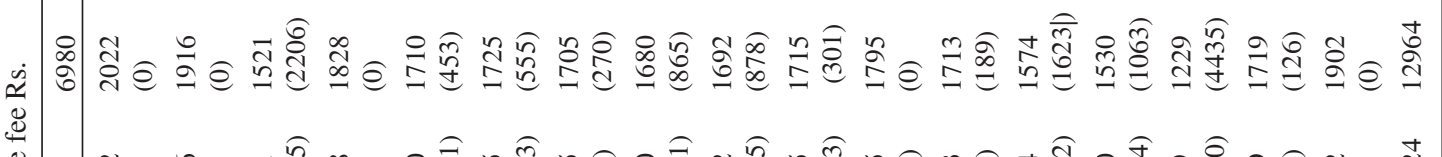

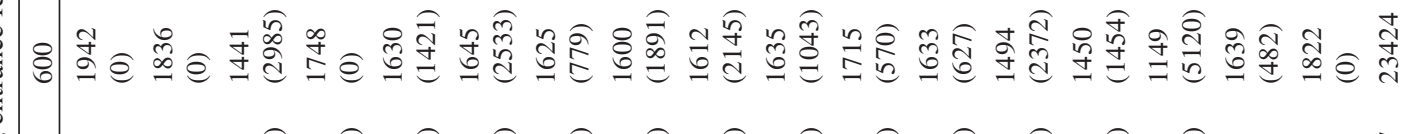

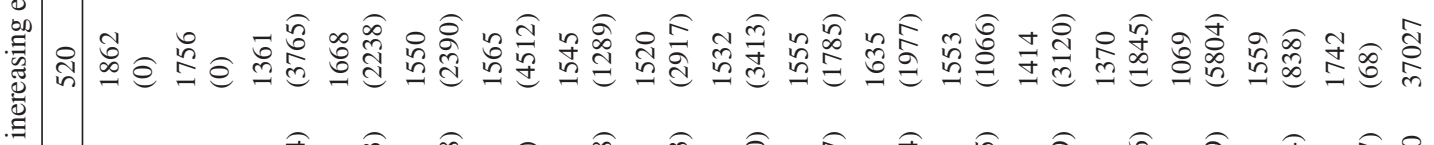

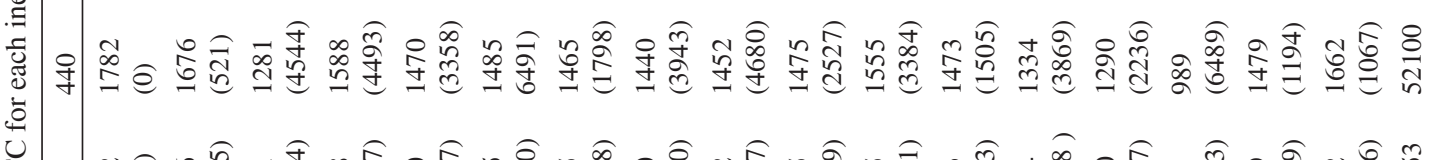

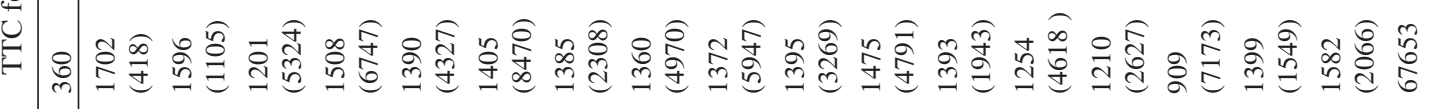

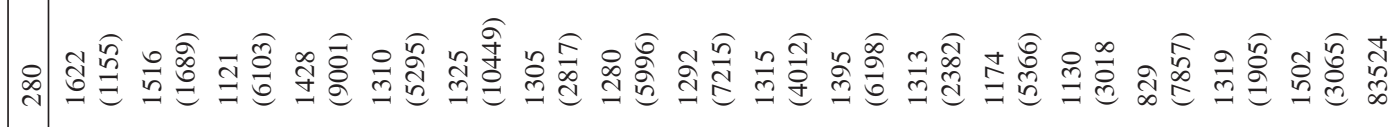

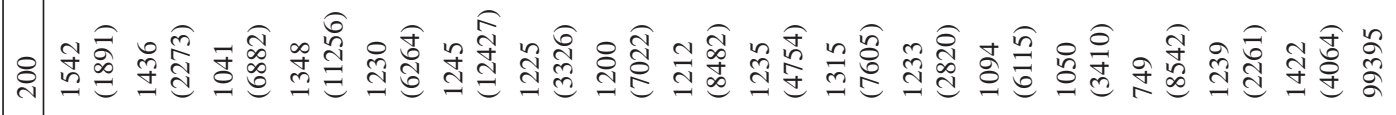

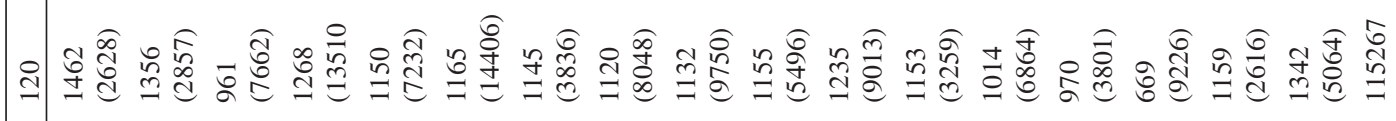

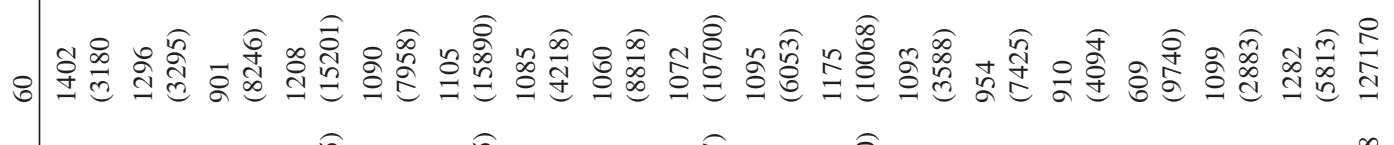

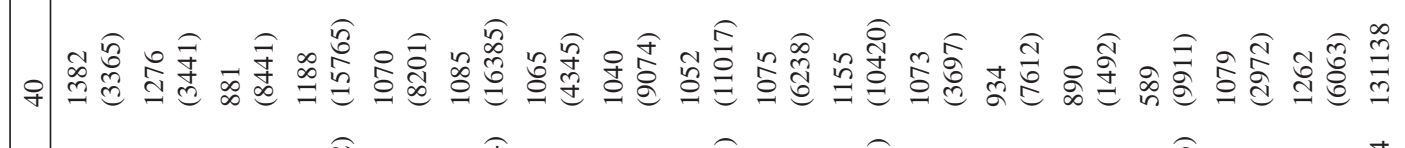

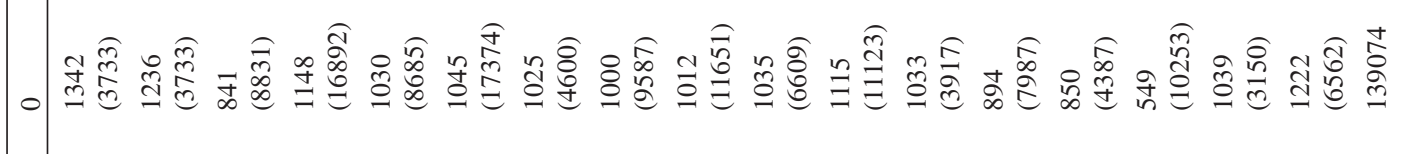

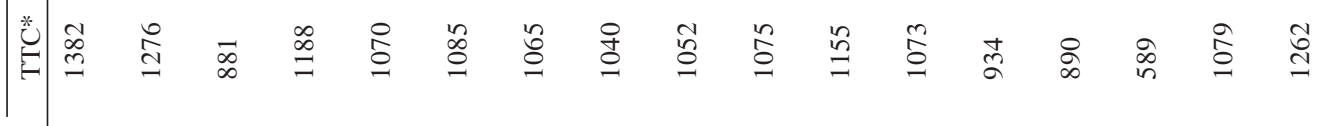

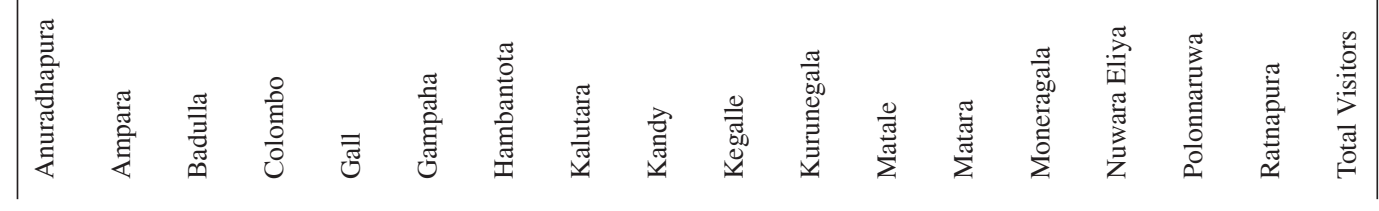


Rathnayaka \& Gunawardena /Journal of Tropical Forestry and Environment Vol. 01, No. 01 (2011) 71-86

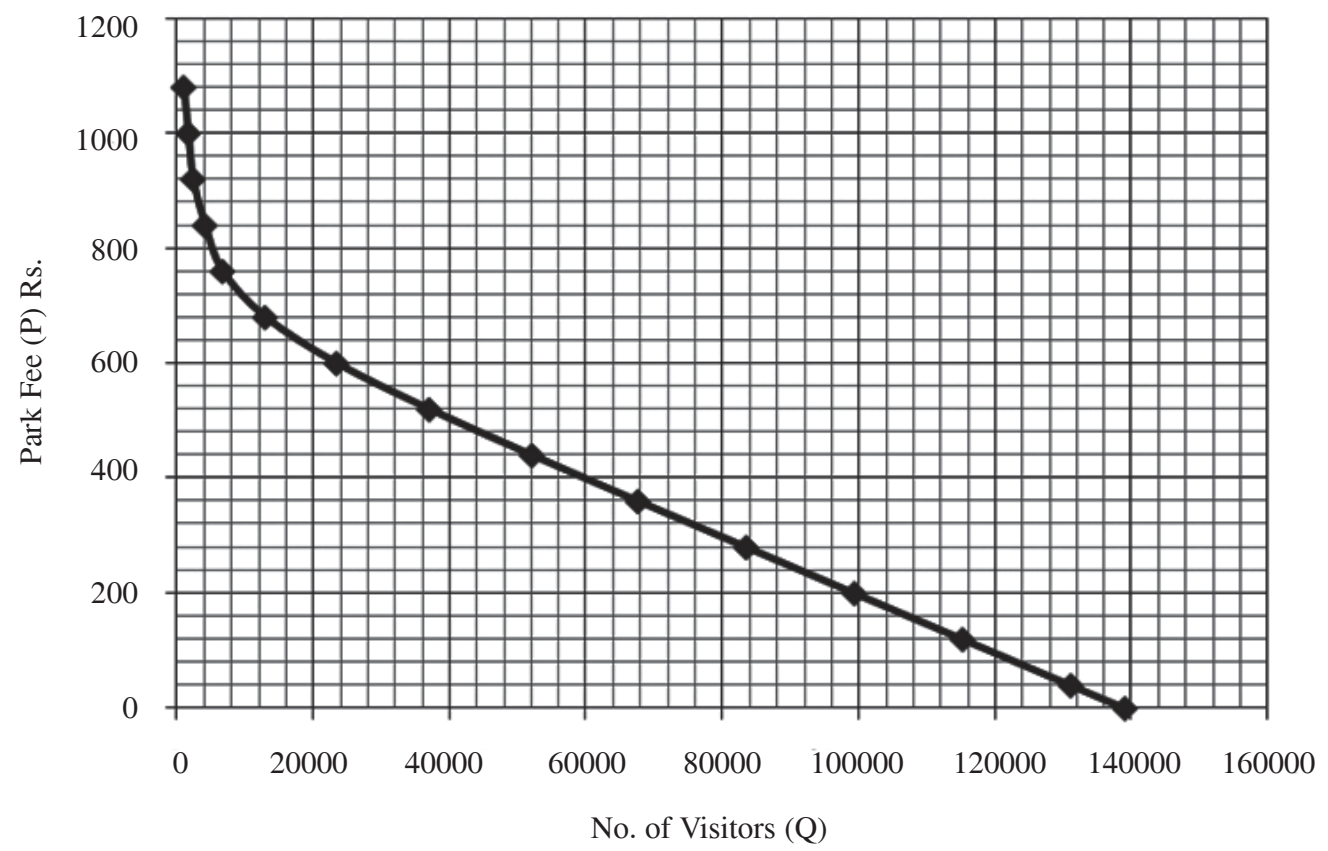

Figure 4: Demand curve for wildlife viewing in HPNP

Since the regression results were satisfactory, it was used in estimating the demand function for HPNP. The demand function was estimated by estimating the number of visitors (per year) for various levels of entrance fee. At a certain level of the entrance fee, demand will be chocked off and none will visit from that region. Since both these methods give identical results (Dixon and Hufschmidt, 1990), the latter was used in this study. Table 3 shows the visits from each zone at different levels of entrance fee and the aggregate visits. The data is plotted as a graph and was used to calculate the consumer surplus (see Figure 4). The graph was divided into 16 strips and the area of each strip was calculated (assuming that the demand curve is linear between any to points) and summed up (Table 4). The area under the above curve was calculated.

According to the analysis, local recreational value (assuming that park entrance fee is zero) of HPNP is 51.68 million rupees per year in 2007. There are about 139074 local adult visitors per year, and the site is worth about Rs. 371.58 per local visit. The demand function for HPNP is,

$$
\begin{aligned}
& \mathrm{P}=944.137-0.0074699 \mathrm{Q} \\
& (\mathrm{S}=141.249 \quad \mathrm{R}-\mathrm{Sq}=88.3 \% \quad \mathrm{R}-\mathrm{Sq}(\mathrm{adj})=87.5 \%) \\
& \mathrm{P}=944-0.00747 \mathrm{Q} \ldots \ldots \ldots \ldots \ldots \ldots \ldots \ldots \ldots \ldots \ldots \ldots \ldots \ldots \ldots \ldots \ldots \ldots \ldots \ldots \ldots \ldots \ldots \ldots \ldots \ldots \ldots \ldots \ldots \ldots \ldots \ldots \ldots \\
&
\end{aligned}
$$

According to formulae (15),

$\mathrm{Q}=\mathrm{a} / 2 \mathrm{~b}$ 
Table 4: Calculation of the area under the demand curve

\begin{tabular}{lr}
\hline Computation & Consumer Surplus \\
\hline$(1 / 2 \times 329 \times 80)+(329 \times 1160)$ & 394800 \\
$(1 / 2 \times 684 \times 80)+(684 \times 1080)$ & 766080 \\
$(1 / 2 \times 685 \times 80)+(685 \times 1000)$ & 712400 \\
$(1 / 2 \times 684 \times 80)+(684 \times 920)$ & 656640 \\
$(1 / 2 \times 1738 \times 80)+(1738 \times 840)$ & 1529440 \\
$(1 / 2 \times 2604 \times 80)+(2604 \times 760)$ & 2083200 \\
$(1 / 2 \times 6240 \times 80)+(6240 \times 680)$ & 4492800 \\
$(1 / 2 \times 10460 \times 80)+(10460 \times 600)$ & 7112800 \\
$(1 / 2 \times 13603 \times 80)+(13603 \times 520)$ & 7617680 \\
$(1 / 2 \times 15073 \times 80)+(15073 \times 440)$ & 7235040 \\
$(1 / 2 \times 15553 \times 80)+(15553 \times 360)$ & 6221200 \\
$(1 / 2 \times 15871 \times 80)+(15871 \times 280)$ & 5078720 \\
$(1 / 2 \times 15871 \times 80)+(15871 \times 200)$ & 3809040 \\
$(1 / 2 \times 15872 \times 80)+(15872 \times 120)$ & 2539520 \\
$(1 / 2 \times 15871 \times 80)+(15871 \times 40)$ & 1269680 \\
$(1 / 2 \times 7936 \times 40)$ & 158720 \\
User Value $($ Consumer Surplus $)-2007$ & Rs. 51677760 \\
\hline
\end{tabular}

Since a is 944 and b is 0.00747 , Q is 63186.077. Substituting this into formulae no. 15 will result in $P$ value of Rs. 472.00 which is the entrance fee, which maximizes the total revenue. Total revenue at this entrance fee will be Rs. Rs.29823792.00. The proposed optimum park entry fee will result in reduction of total number of visitors by $64.9 \%$ (85090), it will yet maximize the total revenue of the park by 314.3 $\%$ (Rs. 16488272.00). Generally, with increasing the entrance fee the number of visitors to the park reduces. It is argued that people who are poor or with marginal income level are not motivated to visit the HPNP with increasing the park entrance fee. Objectives of tourism with interpretation are enjoyment and conservation education. Conservation education is important, because it leads the visitors to conserve biodiversity. Therefore increase of park entrance fee may constrain the visitor's right of enjoyment and conservation education opportunities. In the study it is revealed that the mean monthly income of visitors is about Rs 18,000.00. Therefore, visitors are not at the poor level or marginal income level.

District level recreational values are given in Table 5, and the highest recreational values (consumer surplus values) are recorded from NuwaraEliya, Gampaha and Colombo. Meanwhile, the lowest recreational values are recorded from Anuradhapura, Ampara and Polonnaruwa, and these districts are relatively far away from the HPNP. Although Gampaha and Colombo districts are far away from the HPNP, the highest recreational values are resulted from these two districts because of high visitation and visitors' high purchasing power. 
Table 5: District level recreational values

\begin{tabular}{lr}
\hline District & Recreational Value \\
\hline Anuradhapura & 0.79 \\
Ampara & 0.92 \\
Badulla & 4.05 \\
Colombo & 5.04 \\
Galle & 3.3 \\
Gampaha & 6.32 \\
Hambantota & 1.57 \\
Kalutara & 3.43 \\
Kandy & 4.42 \\
Kegalle & 2.44 \\
Kurunegala & 3.23 \\
Matale & 1.46 \\
Matara & 3.51 \\
Moneragala & 1.95 \\
Nuwaraeliya & 6.34 \\
Polonnaruwa & 1.16 \\
Ratnapura & 1.75 \\
Total Recreational Value & Rs. Millions 51.68 \\
\hline
\end{tabular}

Recently, all the goods and services including vehicle charges and fuel prices have been increased significantly, but the park entrance fee has not been increased for four years. Therefore, it could be further argued that increase of park entrance fee may not cause harmful sociological implications.

However according to the questionnaire survey, the mean park entrance fee, proposed by visitors is Rs. 80.00. This value is two times higher than present fee. The park entrance fee of Rs. 80.00 proposed by visitors reveals that the present entrance fee has to be changed, although this may be an underestimation, since the respondents could have acted strategically in proposing a park entrance fee.

The value of the present study (Rs 51.68 million) is within the range of the estimated values of the national parks. Compared to other national parks HPNP and Yala National Park records a higher values, mainly due to their higher visitations. Meanwhile, the highest recreational values were recorded for urban recreational areas like Diyawanna Oya (Parliament Ground) because more visitation is found and visitors' expensing capacity is also high.

In this study students and foreigners were excluded to narrow down the scope of the study. Hence, the estimated value is lower than the real value placed by the visitors as a whole on experiencing the 
wilderness and wildlife viewing of HPNP. Another problem of the study was that most of the visitors do not visit HPNP only, but visit it as a part of a tour, which consists to visits of many such sites. Use of Travel Cost of such visitors in the study gives an over estimation of the real value of HPNP.

Travel cost method also uses existing markets, determining a person's value of an environmental good from what they spend on travelling in terms of time, travel expenditures and entry fees. Travel cost methods are particularly useful for assessing the non-commercial tourism, recreation and leisure values of a protected area. Travel cost methods, however, can be problematic in that they are data intensive, they rely on restrictive assumptions about consumer behaviour (e.g. multifunctional trips), and they are highly sensitive to the statistical methods used.

\section{Conclusion}

The study shows that while the recreational value of HPNP is Rs. 51.68 Million per year, the total economic value could be many times higher than this. According to the records, more than 70 million is invested on the infrastructure improvement of HPNP during the study period, which is a larger investment compared to the value generated by the wildlife parks. These differences strengthen the common argument by both officials and the public regarding insufficient allocation of man power and funds for conservation of the wildlife. Most of the other problems are the result of these limitations. The problem of poaching, man-made fires and gemming, which are viewed as the crucial problems by many, could be reduced to a minimum if the protected area is managed in such a manner so as to provide necessary visitor services and facilities. The present study shows that there is a potential for earning more revenue from tourism at HPNP, and also this study justifies investing more money to conserve those national assets. Fund generating for such an investment will not be a problem as the visitors could bear the cost as they generate a higher utility for their money.

Many argue that these national heritages must be managed better, services must be provided at a subsidized rate and entrance fees to national Parks should not be kept at profit maximization level. One can argue for and against this, but it is obvious that the HPNP has specific issues that need immediate attention. Hence the entrance fee to the HPNP could be revised using the findings of the study. In 2009, the park fee was revised (Rs. 60.00), and according the present study it could be revised again for more revenue generation while conserving the natural assets with low visitor number, because more visitation cause negative impacts on this fragile ecosystem. The ecological and the sociological carrying capacities of the visitors could also be incorporated and entrance fee could be re-calculated. Further research however needed for such integrations. According to the above findings following policy decisions could be taken by the government on natural resources conservation and revenue generation.
i. Nature tourism improvement at HPNP
ii. Recalculate the entry fee for HPNP
iii. More resource allocation (human/funds) for HPNP
iv. Policies for tourism promotion and recreational planning 
Rathnayaka \& Gunawardena /Journal of Tropical Forestry and Environment Vol. 01, No. 01 (2011) 71-86

\section{References}

Abeygunawadena, P. and Kodithuwakku, K. A. S. S. (1992). "Economics of Recreational Value of Royal Botanic Garden". Proceedings of $3^{\text {rd }}$ Regional Workshop on Multipurpose Trees". Kandy, Sri Lanka. 184-1995.

Central Bank of Sri Lanka (CBSL) 2009, Annual Report, CBSL, Colombo, Sri Lanka

Department of Wildlife Conservation (DWC) 1997, Management Plan for Horton Plains National Park, DWC, Colombo, Sri Lanka

Department of Wildlife Conservation (DWC), 2001, Fauna and Flora Protection Ordinance (a Concise Introduction), Colombo

De Silva, K.A.I.D \& Kotagama, H.B. 1997. An Optimal Fee for Entrance to Udawalawe National Park: An Assessment. Tropical Agricultural Research. 9: 317-329.

Forestry Sector Master Plan, (FSMP) 1995, Ministry of Environment, Rajamalwatte, Battramula, Sri Lanka

Hufschmidt, M.M., James, D.E., Meister, A.D., Bower, B.T. \& Dixon, J. A. 1989. Environment, Natural Systems and Development. John Hopkins, Baltimore, USA.

Jayaratne C. T. and Gunawardena U. A. D. P., 2004. Estimation of local recreational value of Hakgala botanical garden, Proceedings of Ninth International Forestry and Environment Symposium of the Department of Forestry and Environmental Science, University of Sri Jayewardenepura, Sri Lanka.

Kariyawasam, D. 1992. Using the Travel Cost Method for Assessing Recreational Benefits in a Biosphere Reserve, The Sri Lanka Forester. XX(3\&4):11-18

Marasinghe, M.S.L.R.P, 2002. An Estimate of the Recreational Value of Yala National Park. The Department of National Planning, Ministry of Policy Development and Implementation., Colombo, Sri Lanka

Marawila, T. D. \& Thibbotuwawa M. (2010). To Develop or to Conserve? The Case of the Diyawanna Oya Wetlands in Sri Lanka. SANDEE working paper No. 52-10. South Asian Network for Development and Environmental Economics. Kathmandu. Nepal

McConnell, K. E. 1985. The economics of outdoor recreation. In: Handbook of Natural Resources and Energy Economics (Ed: A. V. Knesee and J. L. Sweeney), Elsevier Science B.V., Amsterdam, Holland, Vol. 2, pp. 677-722.

Piyadasa, H.T.N.I \& Thiruchelvam S. 2005. An estimation of the recreational value of "Bopath-Ella" in Ratnapura: a travel cost approach. Tropical Agricultural Research 2005 Vol. 17 pp. 162-172

Rathnayake R M W and Gunawardena U. A. D. P. 2002. Estimation of recreational value of the Wasgamuwa National Park, Paper presented at the International Conference on relating the environment to regional development organised by USJ/ SIDA/ SAREC Research Co-operation Project and Ministry of Environment and Natural Resources, Colombo, Sri Lanka,

Rathnayake R M W and Gunawardena U. A. D. P. 2009. Estimation of recreational value of the Kawdulla National Park. Sri Lanka Journal of Real Estate. 2009:September

Sooriyabandara M.G. 2002. Assessment of recreational value of Minneriya National Park: Possibilities of sharing benefits with stakeholder community, MSc thesis, Post graduate Institute of Science, University of Peradeniya.

Tisdell, C.A. 1991. Economics of Environmental Conservation. Elsevier Science Publisher, Amsterdam, Holland, p. 359. 